\title{
ANÁLISE DO PADRÃO ESPACIAL DE ESPÉCIES E DE GRUPOS FLORÍSTICOS ESTABELECIDOS EM UM POVOAMENTO DE Araucaria angustifolia E EM UMA FLORESTA OMBRÓFILA MISTA NO CENTRO-SUL DO PARANÁ
}

\author{
Rafael Rode ${ }^{1}$, Afonso Figueiredo Filho ${ }^{2}$, Sebastião do Amaral Machado ${ }^{3}$, Franklin Galvão ${ }^{3}$ \\ ${ }^{1}$ Eng. Florestal, M.Sc., Cientec Consultoria e Desenvolvimento de Sistemas, Viçosa, MG, Brasil - rrode@ @reapr.org.br \\ ${ }^{2}$ Eng. Florestal, Dr., Depto. de Engenharia Florestal, UNICENTRO, Irati, PR, Brasil - afonso.figueiredo@pq.cnpq.br \\ ${ }^{3}$ Eng. Florestal, Dr., Depto. de Ciências Florestais, UFPR, Curitiba, PR, Brasil - samachado@ufpr.br - fgalvao@ufpr.br \\ Recebido para publicação: 30/06/2008 - Aceito para publicação: 03/02/2010
}

\begin{abstract}
Resumo
A estrutura espacial de seis grupos florísticos e das espécies arbóreas de maior valor de importância em cada grupo, estabelecidas sob um povoamento de Araucaria angustifolia (A) e em uma Floresta Ombrófila Mista (B), localizados no centro-sul do Paraná foram avaliadas. As parcelas permanentes em A e B têm10 e 25 ha em blocos contínuos de $100 \mathrm{~m}$ x $100 \mathrm{~m}$. Todos os indivíduos com diâmetro à altura do peito acima de $10 \mathrm{~cm}$ foram posicionados espacialmente. Um bloco de cada grupo foi selecionado para avaliar a distribuição espacial, utilizando a função K de Ripley para os testes de Completa Aleatoriedade Espacial e Completa Independência Espacial. Para todos os indivíduos, os grupos em A tiveram aleatoriedade espacial, enquanto que o padrão agrupado foi identificado nos grupos de B. A independência espacial, das principais espécies foi observada quando a cobertura das araucárias foi menos intensa. Com aumento da densidade, observou-se maior competição entre as espécies, identificadas pela dependência espacial, inibição e atração. Em B, as espécies avaliadas acompanharam o padrão de distribuição dos grupos. Merece destaque Ilex paraguariensis pela alta plasticidade nos quatro grupos da B, de forma agrupada e com dependência espacial, na presença de Araucaria angustifolia e Nectandra grandiflora.

Palavras-chave: Função K de Ripley; análise espacial; floresta com araucária; povoamento de araucária.
\end{abstract}

\begin{abstract}
Spatial pattern analysis of species and floristic groups established in an Araucaria angustifolia stand and in a Mixed Rain Florest in the center-south of Paraná. The spatial structure of six floristics groups and the main arboreal species established in an Araucaria angustifolia stand (A) and a Mixed Rain Forest (B) located in Parana State, Brazil was evaluated. Permanet plots in A and B have 10 and 25 ha in continuous blocks of 100 $\mathrm{m}$ x $100 \mathrm{~m}$. All trees with diameter (dbh) above $10 \mathrm{~cm}$ were positioned spatiality. A block of each group was selected to evaluate the spatial structure, using the Ripley's K function, for the tests of Complete Spatial Randomness and Complete Spatial Independence. Groups in A had spatial random ness, when considered all the individuals, while the clustering pattern was identified in the B groups. The spatial independence of the main species was observed when the covering of the "araucarias" was less intense (A). With the density increases (A), larger competition was observed among the species, identified by the spatial dependence, inhibition and attraction. In B, the appraised species accompanied the pattern of distribution of the groups. It deserves prominence Ilex paraguariensis for the discharge plasticity in the four groups of the B in a grouped way and with spatial dependence, in presence of Araucaria angustifolia and Nectandra grandiflora.

Keywords: Ripley's K function; spatial analysis; araucaria forest; araucaria stand.
\end{abstract}

\section{INTRODUÇÃO}

Avaliar o espaço ocupado por indivíduos auxilia no entendimento do sucesso do estabelecimento e reprodução de uma espécie (CONDIT et al., 2000; CAPRETZ, 2004), nos estudos da fenologia, que são pré-requisitos essenciais para entender o potencial da regeneração (FOX, 1976), ainda, na compreensão de hipóteses propostas para explicar como a diversidade local é produzida ou mantida (ou ambos). Como 
exemplo, pode ser citado a hipótese de "chances iguais", em que espécies iguais ou semelhantes na habilidade de colonizar inibem invasores e resistem às vicissitudes do ambiente (CONNELL, 1978).

O padrão de distribuição espacial das espécies em determinada área reflete diferentes influências nas limitações de variáveis ambientais existentes em cada sítio (CAMARERO et al., 2000). Isto é possível, pois a distribuição entre os indivíduos ou é agregada ou dispersa, podendo ocorrer ainda de forma regular ou uniforme (ODUM, 1983; PENTTINEN et al., 1992; CRESSIE, 1993; CONDIT et al., 2000).

Ripley (1977) propôs um método para avaliar padrões espaciais de qualquer evento em determinado espaço baseado em processos de Poisson, denominando-o de função K. O método avalia os eventos em diferentes escalas simultaneamente, trazendo maior flexibilidade em relação a outros métodos (ANJOS et al., 1988; KUULUVAINEN; ROUVINEN, 2000; CAPRETZ, 2004).

Assim, processos pontuais utilizando coordenadas das árvores em uma floresta podem ser utilizados na função K para avaliação do grau de interação entre as árvores (PENTTINEN et al., 1992), na descrição da estrutura espacial de populações menos alteradas (CAMARERO et al., 2000), ou de florestas submetidas a diferentes condições de manejo (BATISTA; MAGUIRE, 1998; CUNHA, 2003), e, ainda, quando avaliando grupo de espécies em diferentes populações (CAPRETZ, 2004), ou para uma espécie em particular (PEREIRA et al., 2006).

Batista; Maguire (1998) utilizaram a função K de Ripley para modelar a estrutura espacial de uma Floresta Atlântica em Linhares, estado do Espírito Santo, submetida a diferentes regimes de manejo.

Camarero et al. (2000) estudaram a estrutura espacial de Pinus uncinata nos Pirineus centrais da Espanha com a função K de Ripley, procurando descrever os processos ecológicos mais atuantes. Os resultados permitiram concluir que os principais fatores atuantes no padrão de distribuição espacial das árvores foram as avalanches e os ventos fortes.

Cunha (2003) utilizou a função K como critério espacial para testar a viabilidade de um método de controle de corte de árvores na Floresta Nacional de Tapajós, estado do Pará.

Anjos et al. (2004), utilizando a função K de Ripley para analisar o padrão de distribuição de Araucaria angustifolia no estado do Paraná, verificaram predomínio de padrão agregado nas áreas com araucária e campo, e padrões diferenciados nas parcelas em áreas com araucária e imbuia. Por se tratar de uma espécie dióica, os autores recomendaram a adição da variável sexo do indivíduo nas análises de distribuição espacial.

Capretz (2004), estudando o padrão espacial de árvores em quatro formações florestais no litoral sul do estado de São Paulo, com uso da função K, ressaltou o caráter agregado nas florestas tropicais principalmente paras as árvores dominantes.

Pereira et al. (2006) analisaram a distribuição espacial de Cariniana legalis (jequitibá-rosa) na região sudoeste de Minas Gerias. Utilizando a função de Ripley, verificaram que não existe dependência espacial entre os indivíduos adultos e a regeneração dessa espécie, em que para os adultos (DAP de 5 a 20 $\mathrm{cm}$ ) foi identificada a distribuição aleatória e para a regeneração (DAP de 0 a $5 \mathrm{~cm}$ ) a distribuição agregada.

Assim sendo, o conhecimento do padrão de distribuição espacial de uma espécie ou de grupos de espécies é relevante para entender processos sucessionais e ecológicos, os quais são fundamentais para a compreensão de um sistema florestal, possibilitando, com isto, a adoção de medidas de manejo que possam preservar ou conservar a floresta.

Este estudo objetivou analisar a estrutura espacial de seis grupos florísticos e das espécies arbóreas de maior valor de importância em cada grupo, estabelecidos sob um povoamento de Araucaria angustifolia e em uma Floresta Ombrófila Mista, localizados na Floresta Nacional de Irati, no centro-sul do Paraná.

\section{MATERIAIS E MÉTODOS}

\section{Local de estudo}

O estudo foi realizado na Floresta Nacional de Irati (FLONA de Irati), na região centro-sul do estado do Paraná, no Segundo Planalto, distante $150 \mathrm{~km}$ de Curitiba. A área encontra-se a $830 \mathrm{~m}$ s.n.m., na posição geográfica de $25^{\circ} 26^{\prime} \mathrm{S}$ e $50^{\circ} 36^{\prime} \mathrm{W}$. 
A FLONA de Irati foi criada em 1942, e se constitui em uma Unidade de Conservação Federal vinculada ao Instituto Chico Mendes. Possui uma área total de 3.495 hectares, sendo 57,6\% ocupada por florestas com predominância de araucária e 37,5\% por plantios estabelecidos principalmente entre as décadas de 1940 a 1960 com Pinus elliottii (658,04 ha), Araucaria angustifolia (417,94 ha), Pinus taeda (96,68 ha), dentre outras (DISPERATI, 1986).

O clima da região, baseando-se na classificação de Köppen, é do tipo $\mathrm{C} f b$ - subtropical úmido mesotérmico, caracterizado por verões frescos, geadas severas e freqüentes e sem estação seca.

Entre as décadas de 1940 e 1950 foi realizado corte raso em parte da Floresta Ombrófila Mista originalmente existente, sendo, então, estabelecidos plantios com Araucaria angustifolia. Esses plantios foram desbastados ao longo dos anos, tendo-se atualmente uma densidade que permitiu a regeneração espontânea de espécies nativas, dando hoje um aspecto de vegetação natural a esses talhões.

Antes da criação da FLONA, a outra parte da Floresta Ombrófila Mista existente sofreu exploração seletiva, mas desde então foi protegida.

\section{Descrição das áreas de pesquisa e coleta de dados}

Os dados utilizados nesta pesquisa são oriundos de duas áreas de pesquisa, A e B (Figura 1), constituídas por blocos contínuos de 1 ha $(100$ m x 100 m), instados com teodolito.

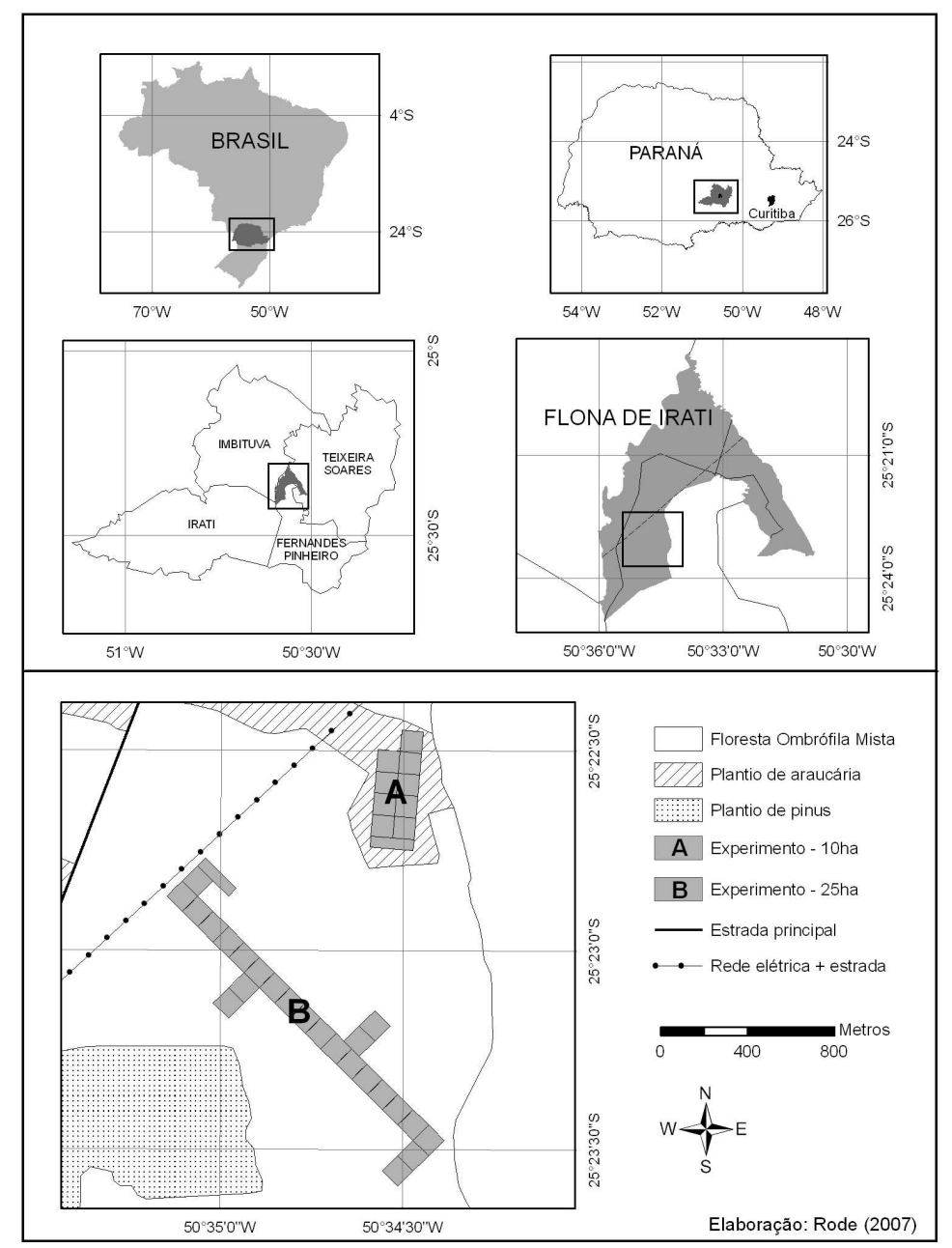

Figura 1. Localização das áreas estudadas na FLONA de Irati, PR.

Figure 1. Location of the research areas in the FLONA of Irati, PR. 
A área $\mathrm{A}$, com 10 ha, e a $\mathrm{B}$, com 25 ha, diferem entre si principalmente por se tratarem, respectivamente, de um povoamento de Araucaria angustifolia implantado há 60 anos e um remanescente de Floresta Ombrófila Mista explorada seletivamente há mais de 60 anos.

Cada bloco foi ainda dividido em parcelas com 0,25 ha $(50 \mathrm{~m} \times 50 \mathrm{~m})$ e, para facilitar a numeração e o mapeamento dos indivíduos que o compõe, 5 faixas de controle ou subparcelas de 0,05 ha $(10 \mathrm{~m} \times 50 \mathrm{~m})$ foram delimitadas em cada parcela. Todos os indivíduos com diâmetro à altura do peito (DAP) igual ou acima de $10 \mathrm{~cm}$ foram medidos, numerados e identificados. A identificação botânica seguiu o Sistema de Classificação APG II (Angiosperm Phylogeny Group II).

\section{Análise espacial}

Para avaliação da estrutura espacial, foram selecionados dois blocos de 1 hectare na área do povoamento e quatro blocos na de floresta. Os blocos foram escolhidos por serem representativos de seis grupos florísticos, formados por análise multivariada, nos 35 hectares em estudo. A metodologia e os resultados para a formação dos grupos florísticos são apresentados em Rode (2008). A tabela 1 mostra os blocos selecionados em cada grupo florístico, bem como as espécies mais importantes para avaliação do padrão espacial.

Tabela 1. Blocos e espécies selecionadas por grupo florístico nas áreas de pesquisa A (povoamento) e B (floresta).

Table 1. Blocks and species selected by floristic group in the research areas A (stand) and B (forest).

\begin{tabular}{|c|c|c|c|c|c|}
\hline $\begin{array}{l}\text { Área de } \\
\text { pesquisa }\end{array}$ & $\begin{array}{l}\text { Grupo } \\
\text { florístico }\end{array}$ & $\begin{array}{l}\mathbf{N}^{\mathbf{0}} \text {. } \\
\text { bloco }\end{array}$ & Espécie & $\begin{array}{c}\text { Valor de } \\
\text { Importância } \\
(\%) \\
\end{array}$ & $\begin{array}{l}\text { Número de } \\
\text { indivíduos }\end{array}$ \\
\hline \multirow{7}{*}{ Área (A) } & \multirow{3}{*}{1} & \multirow{3}{*}{03} & Araucaria angustifolia (Bertol.) Kuntze & 107,3 & 176 \\
\hline & & & Myrsine umbellata Mart. & 17,1 & 89 \\
\hline & & & Cabralea canjerana (Vell.) Mart. & 13,5 & 90 \\
\hline & \multirow{4}{*}{2} & \multirow{4}{*}{08} & Araucaria angustifolia (Bertol.) Kuntze & 136,4 & 402 \\
\hline & & & Psychotria vellosiana Berg. & 16,5 & 82 \\
\hline & & & Myrsine umbellata Mart. & 15,6 & 46 \\
\hline & & & $\begin{array}{l}\text { Alchornea triplinervia (Spreng.) Müll. } \\
\text { Arg. }\end{array}$ & 12,1 & 69 \\
\hline \multirow{11}{*}{ Área (B) } & \multirow{3}{*}{3} & \multirow{3}{*}{01} & Araucaria angustifolia (Bertol.) Kuntze & 50,7 & 56 \\
\hline & & & $\begin{array}{l}\text { Nectandra grandiflora Nees \& C. Mart. } \\
\text { Ex Nees }\end{array}$ & 20,7 & 63 \\
\hline & & & Ilex paraguariensis A. St.-Hil. & 17,9 & 80 \\
\hline & \multirow{3}{*}{4} & \multirow{3}{*}{24} & $\begin{array}{l}\text { Ocotea porosa (Nees \& C. Mart.) } \\
\text { Barroso }\end{array}$ & 36,7 & 58 \\
\hline & & & Araucaria angustifolia (Bertol.) Kuntze & 30,3 & 50 \\
\hline & & & Ilex paraguariensis A. St.-Hil. & 25,8 & 82 \\
\hline & \multirow{2}{*}{5} & \multirow{2}{*}{10} & Ocotea odorifera (Vellozo) Rohwer & 35,1 & 151 \\
\hline & & & Ilex paraguariensis A. St.-Hil. & 14,3 & 48 \\
\hline & \multirow{3}{*}{6} & \multirow{3}{*}{13} & Araucaria angustifolia (Bertol.) Kuntze & 29,7 & 41 \\
\hline & & & Ilex paraguariensis A. St.-Hil. & 20,3 & 41 \\
\hline & & & Matayba elaeagnoides Radlk. & 19,1 & 44 \\
\hline
\end{tabular}

As coordenadas $\mathrm{X}$ e $\mathrm{Y}$ de cada árvore foram consideradas como um evento dentro do bloco em estudo, para aplicação da função K de Ripley.

Foi testada primeiramente a Completa Aleatoriedade Espacial (CAE) para a função univariada, ou seja, a hipótese nula de que os indivíduos se distribuem de forma aleatória. Esta hipótese atua como uma separação entre padrões, fazendo distinção entre um padrão classificado como regular ou agregado (ANJOS, 2004).

A hipótese de Completa Independência Espacial (CIE) também foi testada para as espécies selecionadas. Neste caso, a função bivariada ou "cruzada" investiga a relação espacial entre dois grupos de árvores. Este teste avalia a independência entre grupos gerados por diferentes processos. Valores 
positivos da função indicam tendências em direção à associação ou atração, e valores negativos remetemse a inibição ou repulsão (CAPRETZ, 2004). Na avaliação de CAE e CIE foram construídos envelopes de confiança a partir de 1000 simulações, sendo, portanto, testadas as hipóteses a um nível de confiança de $99,9 \%$.

Segundo Pelissier; Goreaud (2001), padrões espaciais sobre gráficos com poucas árvores necessitam de mais simulações, porém 1000 simulações são suficientes na maioria das situações.

A escala da janela de distância $\mathrm{s}(\mathrm{m})$ utilizado nesta pesquisa foi de 50 metros, ou seja, a metade de um dos lados $(100 \mathrm{~m})$ dos blocos, por serem quadrados. O estimador de Ripley é um estimador não viciado da função K, para distâncias inferiores à metade do menor lado do retângulo (DIGGLE, 1983, citado por CAPRETZ, 2004). As análises foram geradas com o programa SPPA 2.0 desenvolvido por Peter Haase (HAASE, 2004).

\section{RESULTADOS E DISCUSSÃO}

\section{Avaliação da distribuição espacial dos seis grupos florísticos}

É apresentada na figura 2, a distribuição e a análise espacial de todos os indivíduos em cada bloco, selecionados dos grupos florísticos (Tabela 1).

$\mathrm{O}$ envelope de confiança é identificado pelas linhas pontilhadas, sendo sempre uma positiva e outra negativa. $\mathrm{O}$ valor de $\mathrm{K}$ em cada caso é identificado pela linha contínua e de maior espessura. Para aceitar a hipótese de Completa Aleatoriedade Espacial, a linha que indica os valores de $\mathrm{K}$ deve permanecer dentro do envelope de confiança, caso contrário a hipótese é rejeitada e assume-se que o padrão de distribuição dos indivíduos na área é agregado, quando passar do limite superior do envelope (valores positivos), ou regular, quando passar do limite inferior (valores negativos).

Os grupos da área A (1 e 2) possuem, em geral, uma diferenciação em relação aos grupos da área B (3 a 6), por apresentarem os valores de $\mathrm{K}$ dentro dos envelopes de confiança em uma faixa maior. Isto indica que os indivíduos estão distribuídos mais aleatoriamente no povoamento do que na floresta.

Observou-se no grupo 2 um pico de regularidade aos $3 \mathrm{~m}$ da escala (Figura 2b), enquanto que no grupo 1 este pico não chega a passar o envelope de confiança. Isso é decorrência da regularidade das araucárias plantadas, e fica mais evidente quando só os indivíduos desta espécie são avaliados, como poderá ser visto mais adiante.

Nos grupos da floresta, destaca-se o grupo 6 com distribuição aleatória, principalmente após os 20 metros. Para os demais grupos, evidencia-se o agrupamento dos indivíduos, em que no grupo 3, a CAE é rejeitada em toda a escala e, nos grupos 4 e 5 observam-se padrões agregados até 30 e 38 metros, respectivamente.

As diferenças se devem às características específicas de cada grupo. Algumas são mais evidentes, como no caso do grupo 5, com alta ocorrência de $O$. odorifera (151 indivíduos) e por ser característica da espécie apresentar distribuição na forma agregada.

Ainda, os grupos 1 e 2 são diferenciados pelo número de araucárias, ou seja, o bloco 3 selecionado para o grupo 1 tem 176 indivíduos, enquanto que o bloco 8, para o grupo 2, 402 indivíduos (Tabela 1). $\mathrm{O}$ menor número de araucárias cobrindo o dossel naturalmente favorece a regeneração, caracterizado pela tendência ao agrupamento do grupo 1 (Figura $2 b$ ).

\section{Avaliação da distribuição espacial das espécies da área $\mathbf{A}$}

Nas figuras 3 e 4 estão os mapas de distribuição das araucárias plantadas e as principais espécies que se estabeleceram naturalmente dos grupos 1 e 2 . Também são apresentados os gráficos gerados pela função K de Ripley para os casos univariado e bivariado.

No mapa das araucárias plantadas (Figuras 3a e 4a), nota-se a diferença da densidade entre o grupo 1 e o grupo 2, sendo a regularidade do plantio detectada pela função K (Figuras $3 b$ e $4 b$ ). Em ambos os casos ocorrem uma queda ou pico negativo no valor de $\mathrm{K}$ até $10 \mathrm{~m}$, e, portanto, as árvores têm um padrão regular na área. Após $10 \mathrm{~m}$ continua-se observando uma tendência à regularidade, mas os valores de $\mathrm{K}$ já se encontram dentro do envelope de confiança, e aceita-se a hipótese nula de Completa Aleatoriedade Espacial dos indivíduos. 
a)
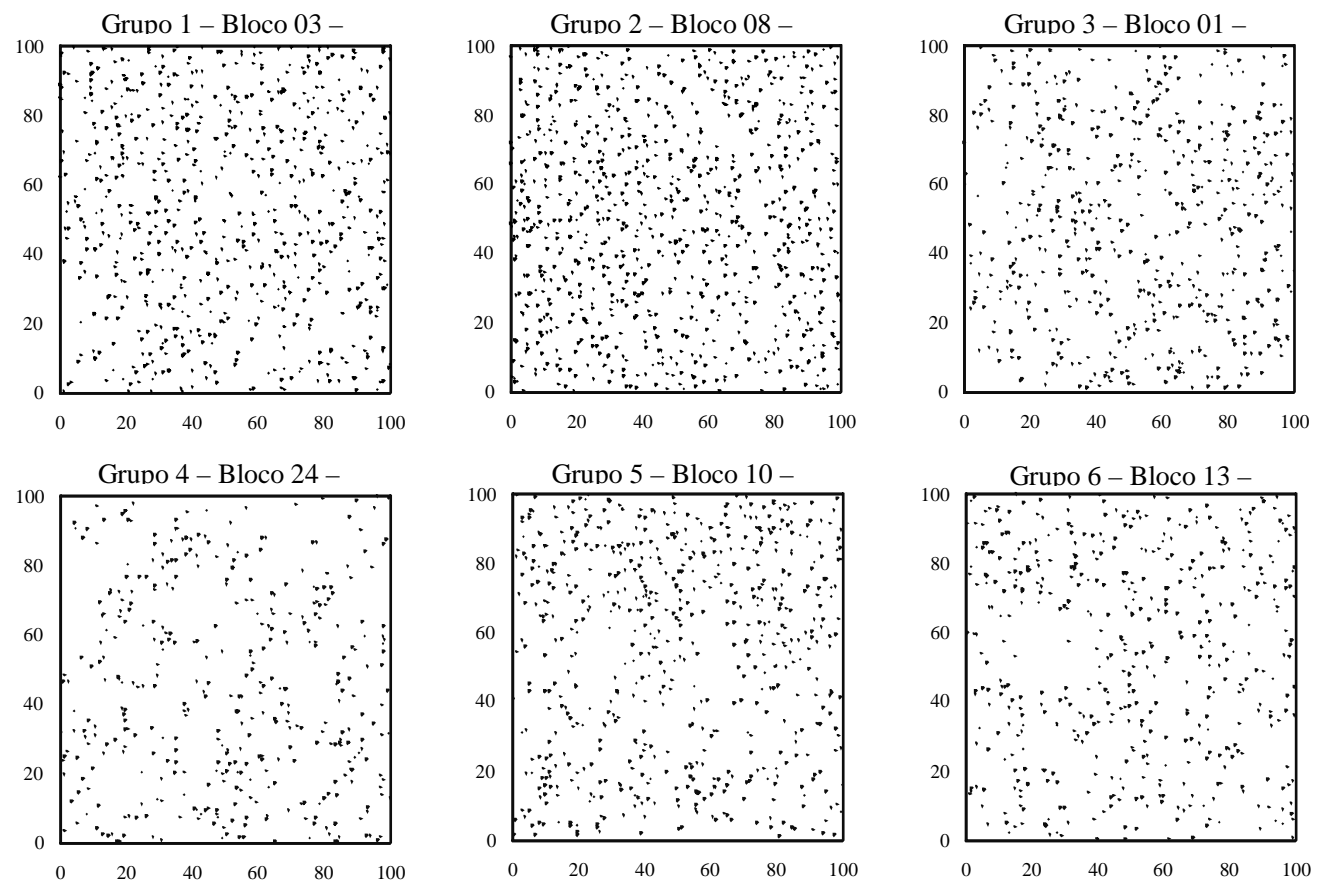

b)
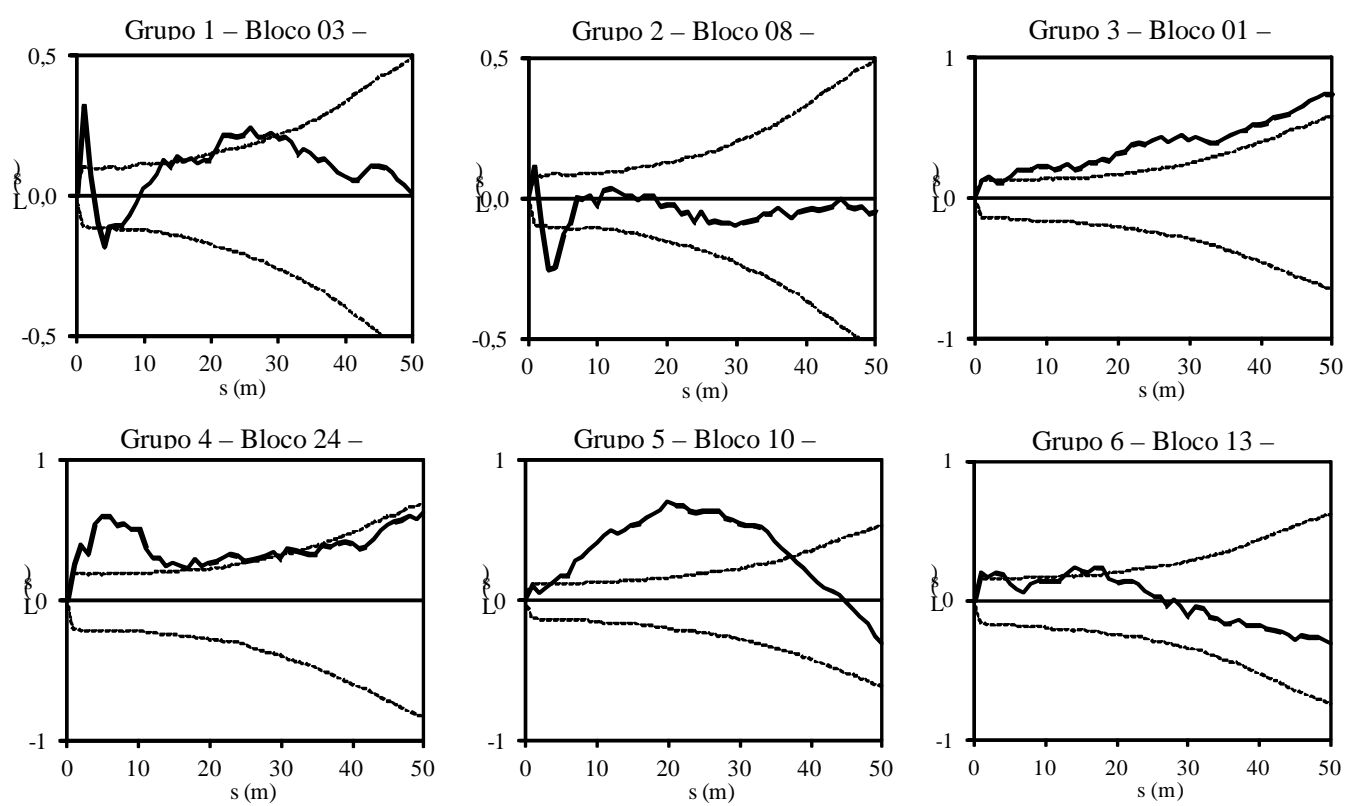

Figura 2. Análise do padrão espacial das árvores para os grupos florísticos das áreas A (povoamento) e B (floresta). a) mapa das espécies; b) análise univariada para CAE; - as linhas tracejadas indicam os envelopes de confiança para $99,9 \%$.

Figure 2. Spatial pattern analysis of the trees for the floristic groups of the areas A (stand) and B (forest). a) map of the species; b) univariate analysis for CAE; - the dash lines indicate the trust envelopes for $99,9 \%$.

Este teste foi realizado também para os outros 9 blocos da área $\mathrm{A}, \mathrm{e}$, em todos os casos, o padrão regular foi observado entre 0 e até $10 \mathrm{~m}$. Portanto, a função K pode ser aplicada para identificar se, em determinada área, 
as araucárias existentes são ou não provenientes de um plantio, mesmo que já tenham recebido alguma intervenção de desbaste. Isto se torna mais interessante quando obtidas coordenadas dos indivíduos a partir de fotografias aéreas ou imagens de satélite, reduzindo e até eliminando o trabalho de campo.

No grupo 1 (Figura 3b), Myrsine umbellata apresentou um padrão agregado entre 6 e $24 \mathrm{~m}$ e Cabralea canjerana tendência a agrupamento a partir de 25 metros. Quando observado o tipo de interação espacial entre estas espécies com as araucárias plantadas (Figura 3c), a hipótese de Completa Independência Espacial é aceita, ou seja, M. umbellata e C. canjerana não têm característica de atração ou repulsão com as araucárias plantadas, inclusive entre elas.

a)

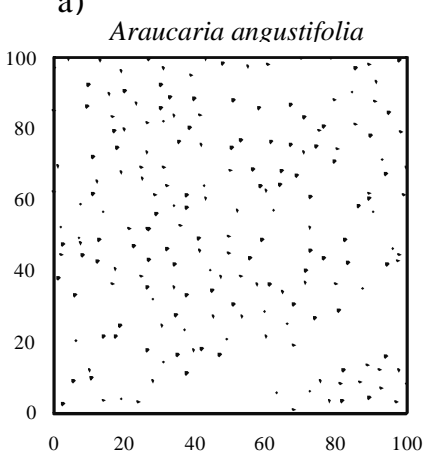

b)

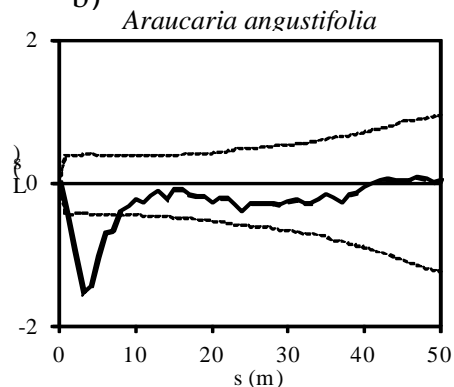

c)

Araucaria angustifolia

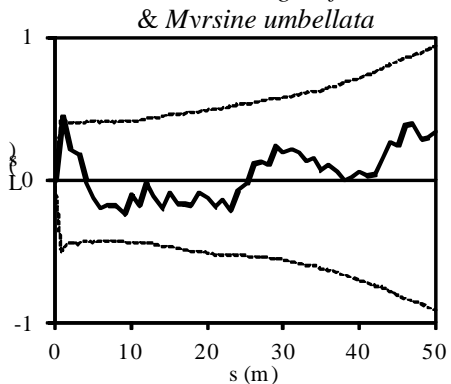

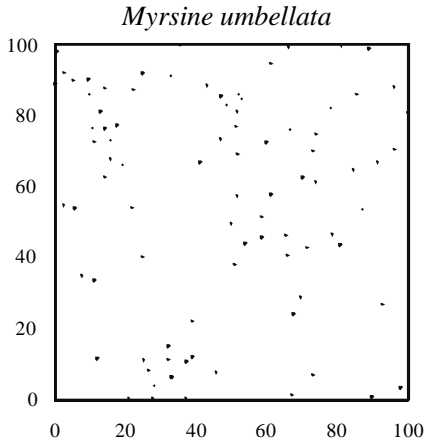
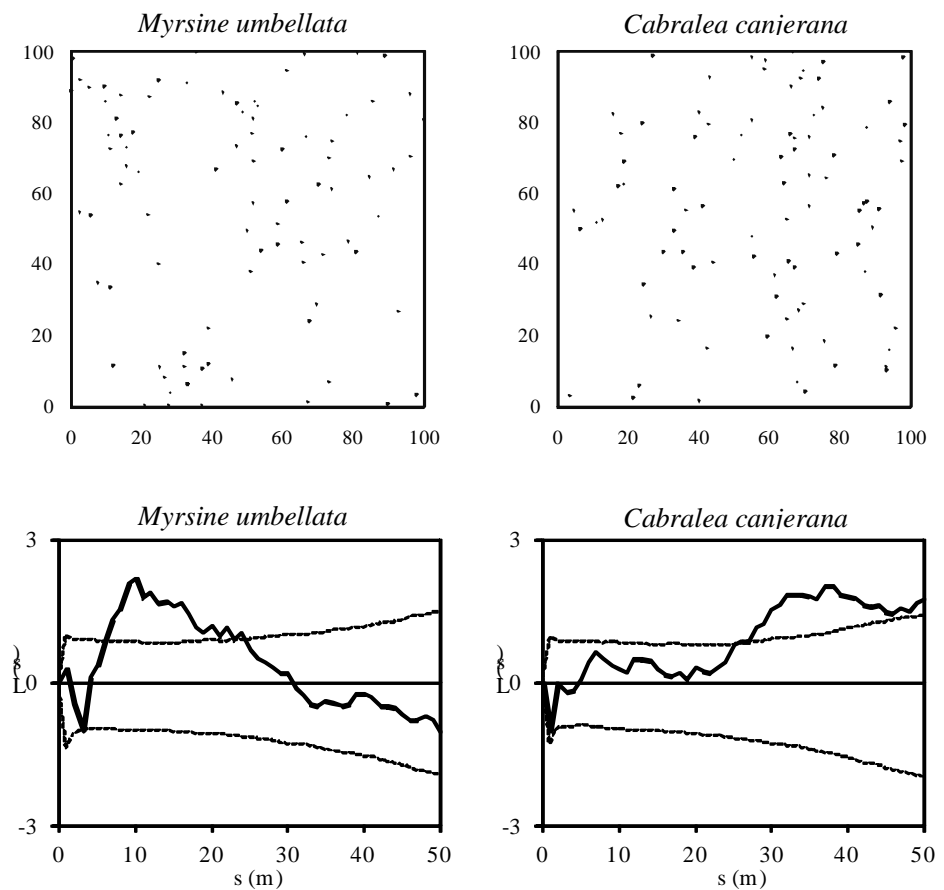

Araucaria angustifolia

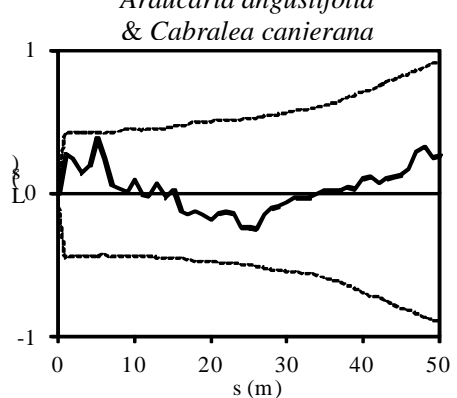

Myrsine umbellata

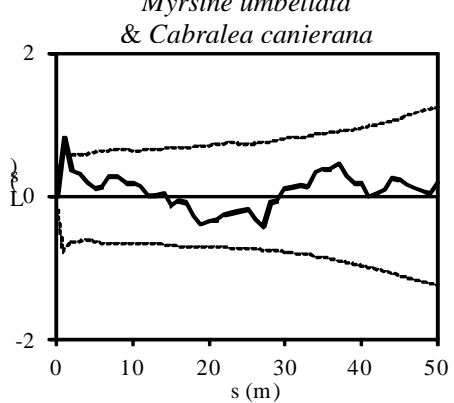

Figura 3. Análise do padrão espacial das principais espécies do grupo 1 (bloco 3). a) mapa das espécies; b) análise univariada para CAE; c) análise bivariada para CIE - as linhas tracejadas indicam os envelopes de confiança para 99,9\%.

Figure 3. Spatial pattern analysis of the main species of group 1 (block 3). a) map of the species; b) univariate analysis for CSR; c) bivariate analysis for CSI - the dash lines indicate the trust envelopes for $99,9 \%$.

No grupo 2 foram avaliadas três espécies importantes da regeneração. Na área A, Psychotria vellosiana encontra-se agrupada entre 8 e $45 \mathrm{~m}$, Myrsine umbellata possui uma tendência a agrupamento a partir de $15 \mathrm{~m}$ e Alchornea triplinervia situa-se em um padrão agrupado (Figura 4b). 
a)
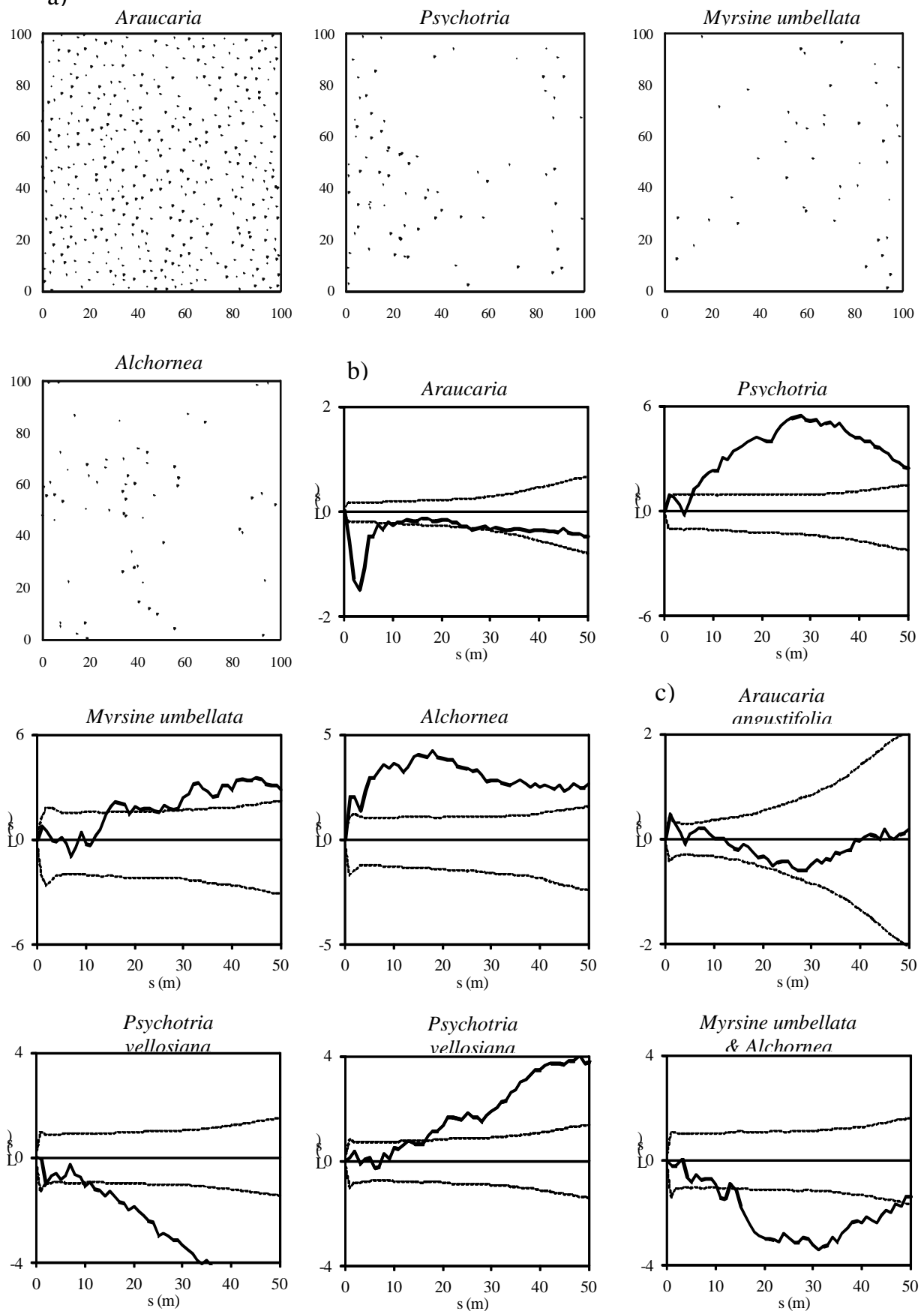

Figura 4. Análise do padrão espacial das principais espécies do grupo 2 (bloco 8). a) mapa das espécies; b) análise univariada para CAE; c) análise bivariada para CIE - as linhas tracejadas indicam os envelopes de confiança para 99,9\%.

Figure 4. Spatial pattern analysis of the main species of group 2 (block 8). a) map of the species; b) univariate analysis for CSR; c) bivariate analysis for CSI - the dash lines indicate the trust envelopes for $99,9 \%$.

Pode-se observar os resultados para o caso bivariado entre as espécies na figura 4c. Avaliando as interações de $P$. vellosiana, $M$. umbellata e A. triplinervia com A. angustifolia, a completa independência espacial foi constatada em todos os casos, e, portanto, somente o gráfico entre A. angustifolia e M. 
umbellata é ilustrado na figura 4c. Esta independência é facilmente compreendida uma vez que as araucárias plantadas estão presentes em toda a área $\mathrm{A}$, ou seja, não há espaço para estabelecimento de espécies que competem, por exemplo, pelos mesmos níveis de nutrientes e intensidade luz. Assim, não é esperado que a função $\mathrm{K}$ detecte níveis de repulsão entre espécies.

Na interação entre as demais espécies (Figura 4c), M. umbellata teve repulsão com P. vellosiana, após $10 \mathrm{~m}$, e com $A$. triplinervia, apresentou independência entre 0 e $15 \mathrm{~m}$ e repulsão após $15 \mathrm{~m}$.

Quando se avalia $P$. vellosiana e A. triplinervia, o oposto é observado. Os valores de $\mathrm{K}$ passam a ser positivos e a atração entre as duas espécies é identificada após os $18 \mathrm{~m}$. Estes resultados mostram a importância das espécies na interação com o ambiente, podendo trazer interpretações a respeito da autoecologia e dispersão das sementes, bem como a maneira com que duas espécies competem no ambiente.

Segundo Backes; Irgang (2002), os frutos de M. umbellata são consumidos por sabiás, tucanos, jacus, gralha-amarela e outras aves. A semente germina facilmente em qualquer tipo de solo, após os frutos passarem pelo tubo digestivo dos animais que os consomem. Trata-se de uma espécie pioneira e facultativa, estabelecendo-se em áreas campestres, capoeiras, ou mesmo compondo fases sucessionais mais avançadas.

A dispersão de frutos e sementes de A. triplinervia é principalmente ornitocórica (CARVALHO, 2003) e participa do banco de sementes do solo. Caracteriza-se como espécie pioneira e facultativa. $P$. vellosiana também é uma espécie facultativa e possui dispersão zoocórica.

Estas três espécies, do grupo 2, possuem características ecológicas semelhantes, isto explica, em parte, porque a interação ocorreu de forma repulsiva entre elas, com exceção entre $P$. vellosiana e A. triplinervia.

Portanto, uma avaliação da sucessão e dispersão ainda não se mostra suficiente para explicar casos particulares. De fato, para entender a dinâmica sucessional em habitat particular é necessário o conhecimento de quais restrições ambientais estão atuando. As restrições ambientais atuam nos requerimentos que a planta necessita, que podem vir de aproximadamente 20 diferentes recursos essenciais como luz, água, $\mathrm{CO}_{2}, \mathrm{~N}, \mathrm{P}, \mathrm{K}, \mathrm{Ca}, \mathrm{Mg}, \mathrm{S}$ etc. (SCHULZE; MOONEY, 1994).

Para Odum (1983), o isolamento geralmente é o resultado de competição entre indivíduos por recursos reduzidos em oferta, ou de antagonismo direto, envolvendo mecanismos químicos de isolamento (antibióticos e alelopatias) em plantas. Nos dois casos, pode resultar em uma distribuição aleatória ou uniforme, porque vizinhos próximos são eliminados ou expulsos.

Tal conceito pode explicar o motivo de M. umbellata ficar mais competitiva quando observada no grupo 2 (maior densidade), pois, como mencionado, ela está inibindo $P$. vellosiana e também, $A$. triplinervia (Figura 4c), o que não fez com a C. canjerana no grupo 1 (Figura 3c), por haver recursos suficientes para ambas ou terem exigências diferentes, como, por exemplo, pela luz, e, portanto, apresentaram-se de forma independente.

\section{Avaliação da distribuição espacial das espécies da área B}

As análises para os grupos 3 e 6 podem ser observadas, respectivamente, nas figuras 5 e 6 . Os dois grupos são comparados em função de possuírem espécies semelhantes. Observa-se no grupo 3 (Figura 5b) que A. angustifolia ocorre de forma aleatória no bloco, com picos de agregação entre 20 e 35 m. Já, o grupo 6 (Figura 6b) o pico de agregação foi entre 3 e 7 m, sendo então aceita a Completa Aleatoriedade Espacial. A partir dos $30 \mathrm{~m}$ é observada, ainda na figura $6 \mathrm{~b}$, que a espécie possui uma tendência à regularidade, mas permanecendo ainda dentro do envelope de confiança.

O padrão espacial de $N$. grandiflora, no grupo 3, foi aleatório até 23 m (Figura 5b) e, após esta medida, tem um padrão agregado. Esta espécie não pôde ser analisada no grupo 6, pois o número de árvores (31) no bloco não foi suficiente para processar a função K. Níveis de agregação também são observados para I. paraguariensis entre 5 e $20 \mathrm{~m}$, no grupo 3, e entre 5 e $30 \mathrm{~m}$, no grupo 6 . Fora desta escala, a CAE é aceita.

M. elaeagnoides foi avaliada por ter sido importante na formação do grupo 6 e selecionada como discriminante pela análise multivariada. A função K detectou para a espécie uma variação entre aleatório e agregado em toda a escala (Figura 6b).

Avaliando a Função K bivariada entre as espécies (Figuras 5c e 6c), constata-se que $A$. angustifolia possui, em geral, independência espacial entre as demais. Quando ocorre com $I$. paraguariensis, observa-se uma repulsão entre estas espécies em uma faixa entre 28 e $42 \mathrm{~m}$ na escala no grupo 3 (Figura 5c). No grupo 6 (Figura 6c), esta repulsão é observada a partir de 30 metros. 
a)

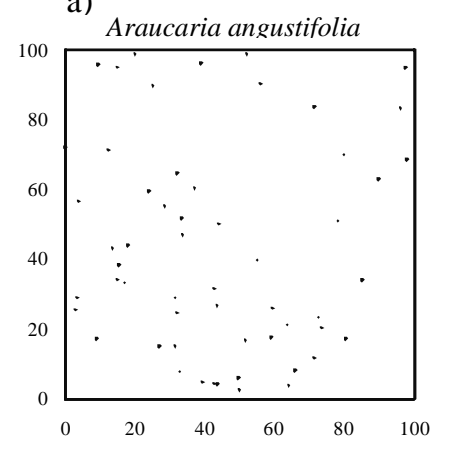

b)

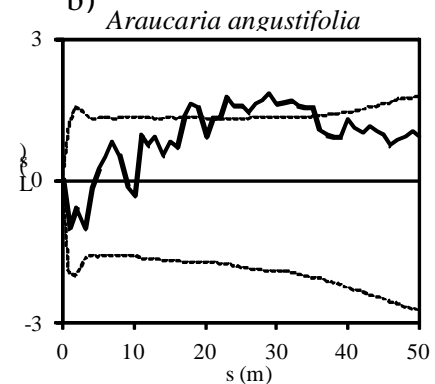

c)

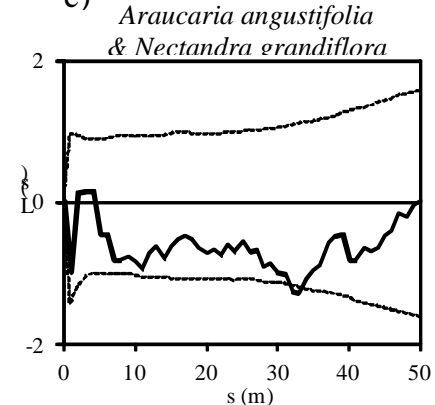

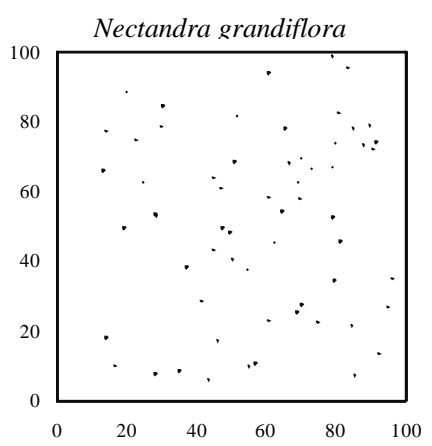
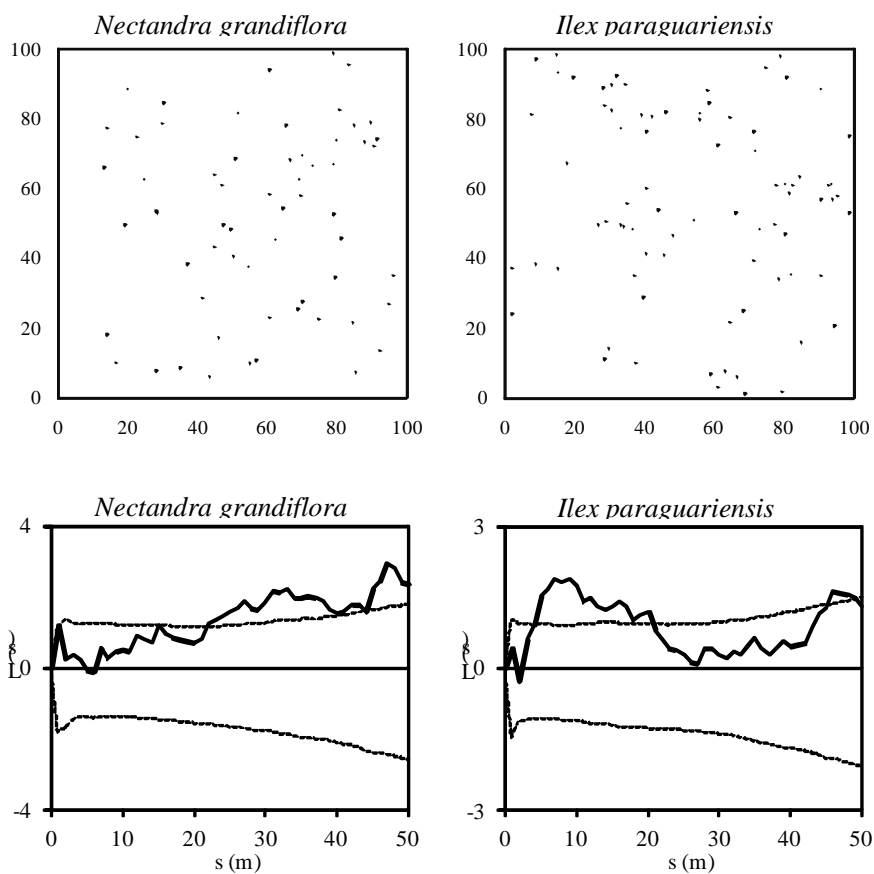

Araucaria angustifolia

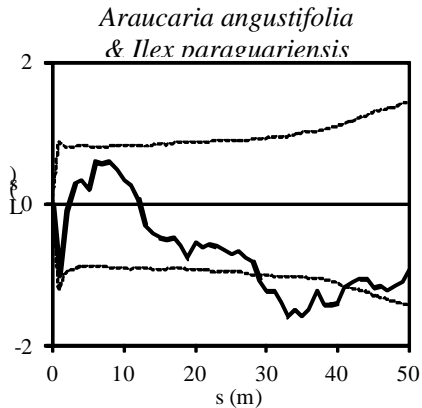

Nectandra grandiflora

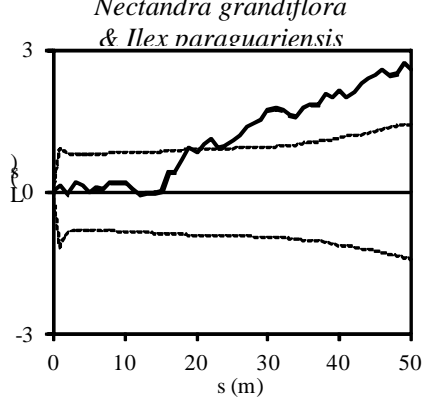

Figura 5. Análise do padrão espacial das principais espécies do grupo 3, (bloco 01). a) mapa das espécies; b) análise univariada para CAE; c) análise bivariada para CIE - as linhas tracejadas indicam os envelopes de confiança para 99,9\%.

Figure 5. Spatial pattern analysis of the main species of group 3 (block 1). a) map of the species; b) univariate analysis for CSR; c) bivariate analysis for CSI - the dash lines indicate the trust envelopes for $99,9 \%$.

Analisando o mapa das duas espécies no grupo 6 (Figura 6a), I. paraguariensis está presente onde ocorre A. angustifolia, mas não em todos os locais onde esta ocorre. Portanto, a função K identificou esta característica, rejeitando a independência espacial após os $30 \mathrm{~m}$. Quando foi avaliada juntamente com N. grandiflora, I. paraguariensis possuiu dependência espacial (atração) após os $20 \mathrm{~m}$ (Figura 5c), mas com M. elaeagnoides, a CIE é rejeitada já aos $5 \mathrm{~m}$, caracterizando, neste caso, a repulsão entre estas espécies no grupo 6 (Figura 6c).

Nestes resultados, observa-se a influência de M. elaeagnoides na diferenciação dos grupos 3 e 6 , e uma questão é levantada a respeito desta espécie: I. paraguariensis possui capacidade de atração com $N$. grandiflora, como observado no grupo 3 (Figura 4c), mas possui repulsão com M. elaeagnoides (Figura 5c), ou seja, onde ocorre M. elaeagnoides não ocorre I. paraguariensis, então, ou M. elaeagnoides modificou o ambiente associando-se com A. angustifolia e fazendo com que $I$. paraguariensis tivesse repulsão com A. angustifolia, ou esta característica é por conta de fatores abióticos. 
Segundo Odum (1983), as forças que isolam ou espacejam os indivíduos casais ou pequenos grupos de uma população talvez não ocorram tão amplamente quanto aquelas que favorecem a agregação, mas essas forças, apesar disso, são muito importantes para aumentar o fitness e, possivelmente, também para regular a população.
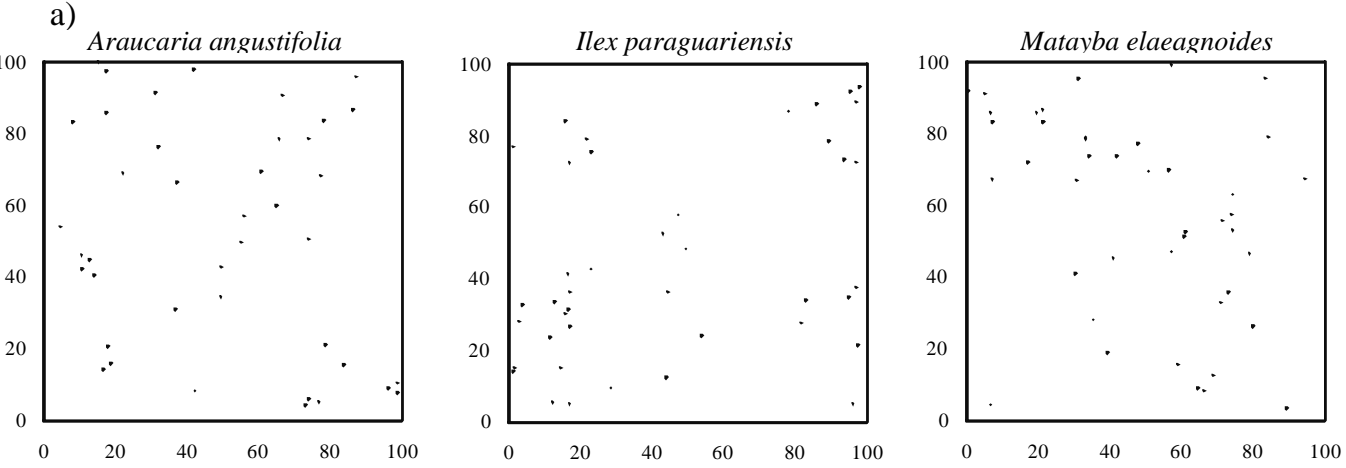

b)
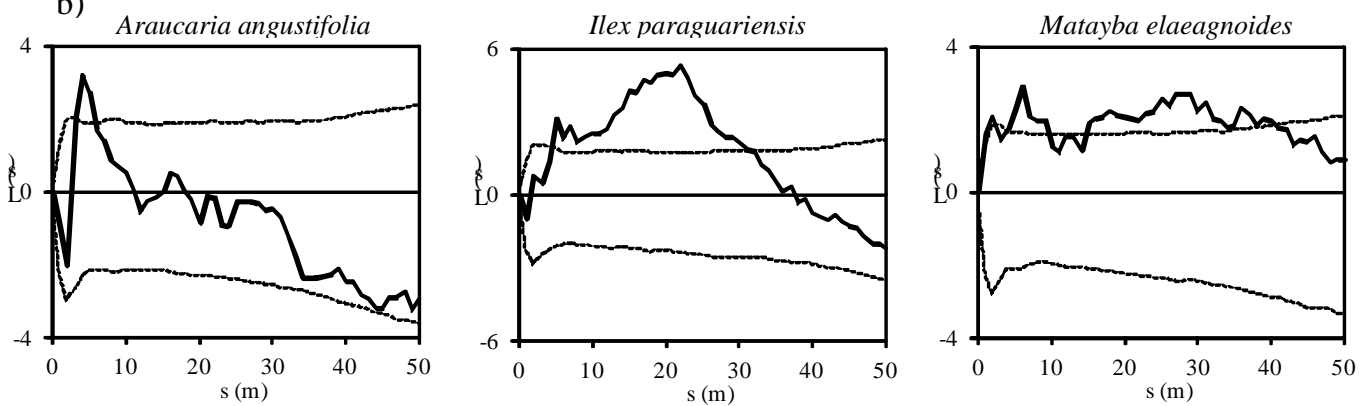

c) Araucaria angustifolia \& Ilex paraguariensis
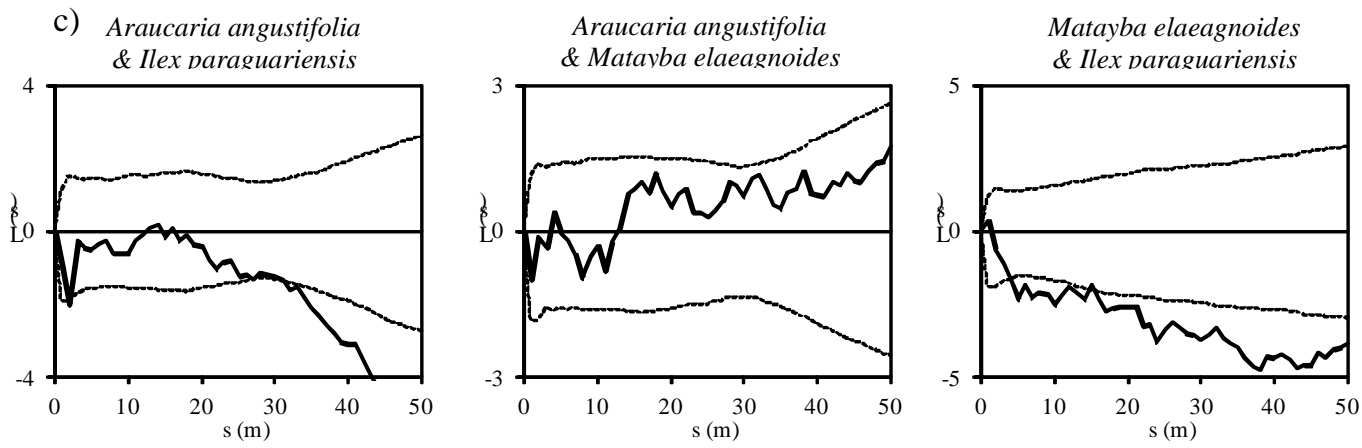

Figura 6. Análise do padrão espacial das principais espécies do grupo 6, (bloco 13). a) mapa das espécies; b) análise univariada para CAE; c) análise bivariada para CIE - as linhas tracejadas indicam os envelopes de confiança para 99,9\%.

Figure 6. Spatial pattern analysis of the main species of group 6 (block 13). a) map of the species; b) univariate analysis for CSR; c) bivariate analysis for CSI - the dash lines indicate the trust envelopes for $99,9 \%$.

A análise do padrão espacial das espécies para os grupos 4 e 5 estão nas figuras 7 e 8 , respectivamente. Observando a função K de Ripley para o grupo 4 (Figura 7b), a CAE é rejeitada em algumas faixas da escala para as três espécies em estudo. O. porosa possui padrão agregado entre 18 e 33 $\mathrm{m}$, A. angustifolia apenas um pico de agrupamento aos $9 \mathrm{~m}$, enquanto que para I. paraguariensis há um agrupamento dos indivíduos numa faixa de 2 a $38 \mathrm{~m}$. 
a)
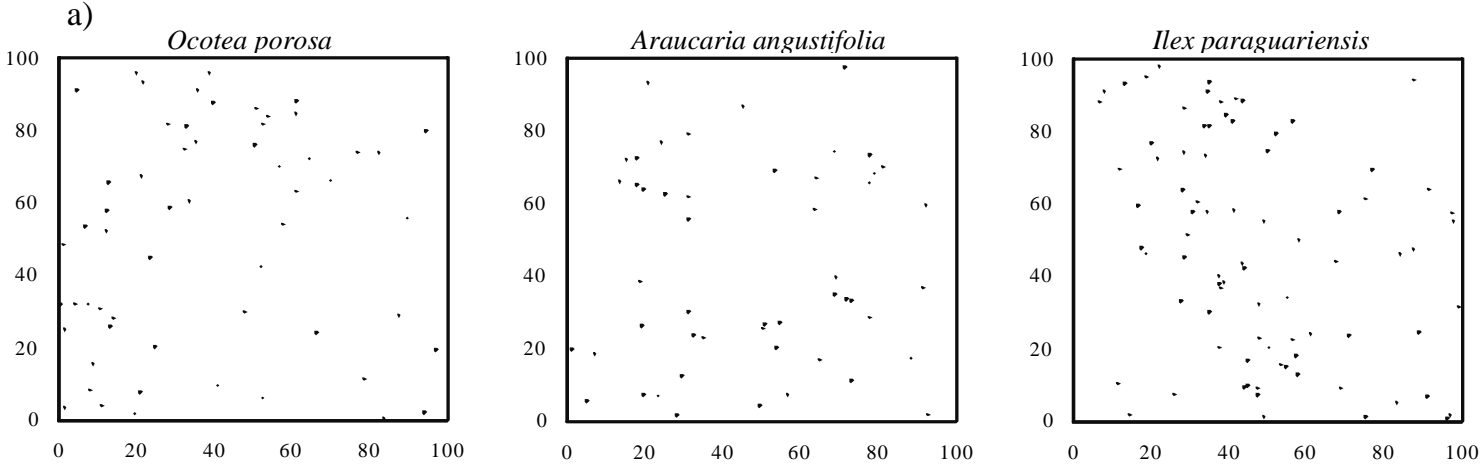

b)
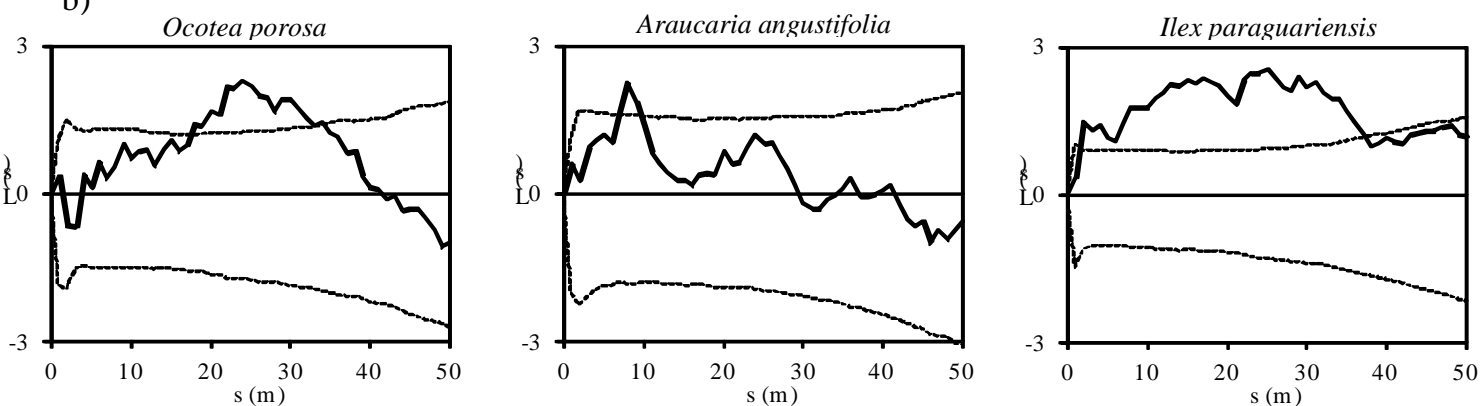

c)

Ocotea porosa \& Araucaria angustifolia
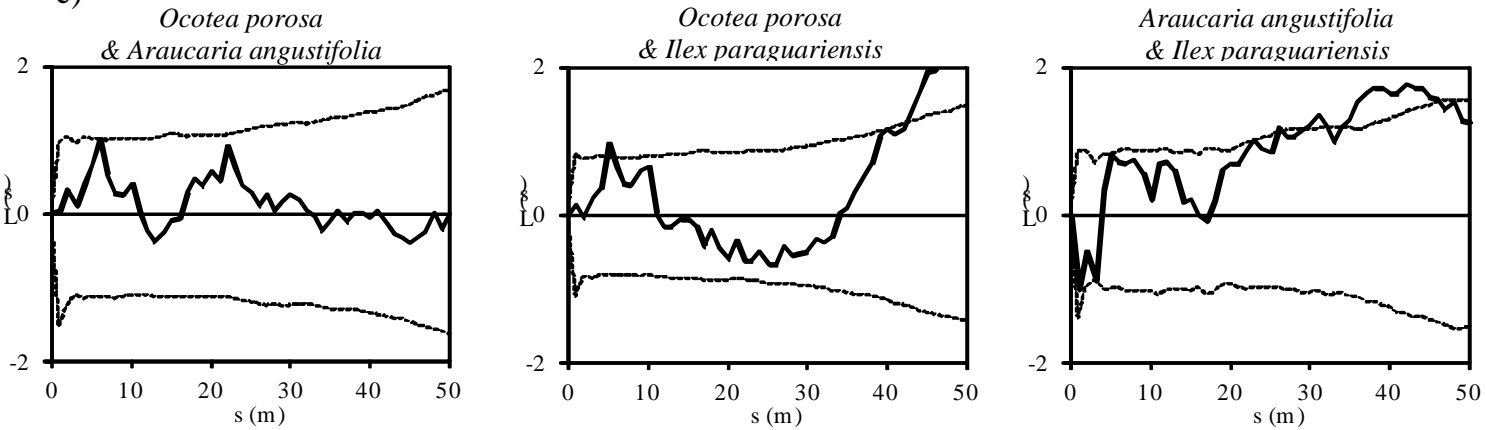

Figura 7. Análise do padrão espacial das principais espécies do grupo 4, (bloco 24). a) mapa das espécies; b) análise univariada para CAE; c) análise bivariada para CIE - as linhas tracejadas indicam os envelopes de confiança para 99,9\%.

Figure 7. Spatial pattern analysis of the main species of group 4 (block 24). a) map of the species; b) univariate analysis for CSR; c) bivariate analysis for CSI - the dash lines indicate the trust envelopes for $99,9 \%$.

Avaliando a dependência espacial destas espécies com a função bivariada (Figura 7c), O. porosa e $A$. angustifolia permanecem dentro do envelope de confiança em toda a escala, portanto se aceita a CIE entre elas. A espécie I. paraguariensis ocorre de forma independente com $O$. porosa, sendo observada atração a partir de $40 \mathrm{~m}$. Quando avaliada juntamente com A. angustifolia teve dependência espacial após $25 \mathrm{~m}$.

O grupo 5 (Figura 8) é avaliado apenas com as duas espécies mais importantes, O. odorífera e $I$. paraguariensis. Isto é justificado pelo fato de que A. angustifolia, que é a terceira mais importante do grupo, apresentar apenas 14 indivíduos neste bloco, não sendo suficiente para processar a função K.

Os indivíduos de $O$. odorifera apresentaram padrão agregado entre 8 e $45 \mathrm{~m}$ e $I$. paraguariensis entre 3 e 23 m (Figura 8b). Quando avaliadas com a função bivariada, pode-se concluir que a CIE entre elas foi aceita em toda escala (Figura 8c). 
a) Ocotea odorifera

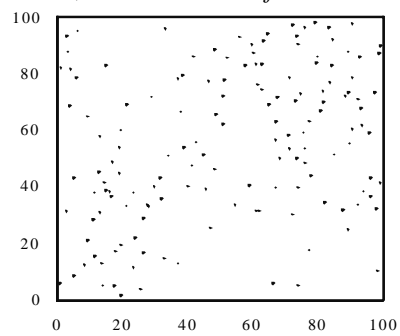

b) Ocotea odorifera

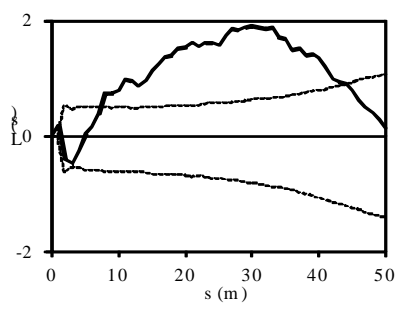

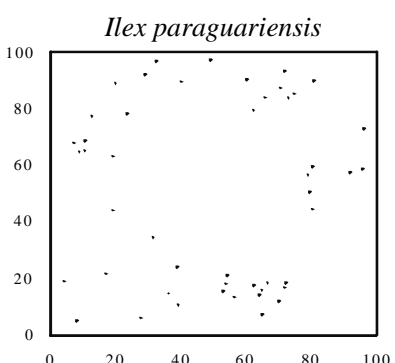

Ilex paraguariensis

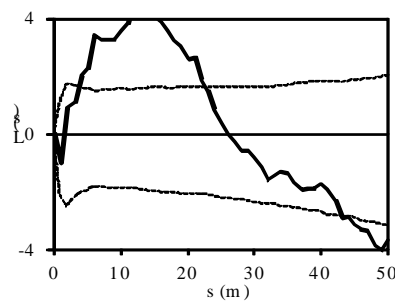

Ocotea odorifera

\& Ilex paraguariensis

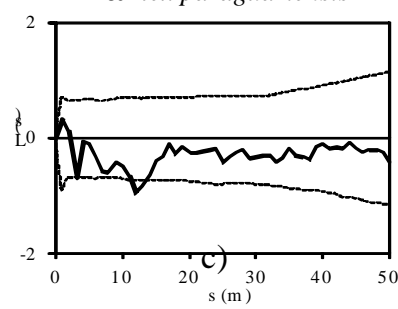

Figura 8. Análise do padrão espacial das principais espécies do grupo 5, (bloco 10). a) mapa das espécies; b) análise univariada para CAE; c) análise bivariada para CIE - as linhas tracejadas indicam os envelopes de confiança para 99,9\%.

Figure 8. Spatial pattern analysis of the main species of group 5 (block 10). a) map of the species; b) univariate analysis for CSR; c) bivariate analysis for CSI - the dash lines indicate the trust envelopes for $99,9 \%$.

\section{CONCLUSÕES}

- A avaliação da distribuição espacial dos indivíduos nos blocos em estudo foi, em linhas gerais, um padrão aleatório para os dois blocos do povoamento com araucária (área A), enquanto que para a floresta com araucária (área B) tiveram o padrão agrupado.

- Para as araucárias plantadas, a função $\mathrm{K}$ de Ripley detectou a regularidade das árvores tanto para o grupo 1, onde há menor densidade, quanto para o grupo 2. Portanto pode ser ressaltada a utilidade desta ferramenta quando se deseja esta informação e quando há dificuldade de identificação visual deste padrão espacial.

- Quando a cobertura das araucárias foi menos intensa (grupo 1), as principais espécies da regeneração tiveram independência espacial. Porém quando a densidade aumenta (grupo 2), observou-se maior competição entre a regeneração, identificado pela dependência espacial, inibição e atração entre as espécies.

- $\mathrm{Na}$ área $\mathrm{B}$, as espécies avaliadas acompanharam, em geral, o padrão de distribuição dos grupos. Merece destaque Ilex paraguariensis pela alta plasticidade apresentada nos quatros grupos, se comportando, na maioria das vezes, de forma agrupada e com dependência espacial (atração) quando encontra Araucaria angustifolia e Nectandra grandiflora.

- São observadas outras diferenças nos padrões espaciais das espécies e, embora haja necessidade de uma análise sucessional em cada grupo, muitos fatores estão envolvidos para melhor esclarecimento destas diferenças. Os aspectos ecológicos, a biologia reprodutiva e a fenologia das espécies são as características mais citadas para o entendimento das estratégias de estabelecimento e ocupação, mas que estarão sempre restritos, principalmente aos fatores abióticos, como intensidade de luz, água, temperatura, tipo de solos e disponibilidade de nutrientes.

\section{REFERÊNCIAS}

ANJOS, A. Análise do padrão de distribuição espacial do palmiteiro (Euterpe edulis) utilizando a função K de Ripley. 1998. 110 p. Dissertação (Mestrado em Agronomia). Escola Superior de Agricultura Luiz de Queiroz, Universidade Federal de São Paulo, Piracicaba. 
BACKES, P.; IRGANG, B. Árvores do sul: guia de identificação \& interesse ecológico. Santa Maria: Palloti, 2002. 326 p.

BATISTA, J. L. F.; MAGUIRE, D. A. Modelling the spatial structure of tropical forests. Forest Ecology and Management, v. 110, p. 293-314, 1998.

BATISTA, J. L. F. Spatial dynamics of trees in a Brazilian atlantic tropical forest under natural and managed conditions. 1994. Thesis (Ph.D.) - University of Washington. Seattle,

CAMARERO, J. J.; GUTIÉRREZ, E.; FORTIN, M. Spatial pattern of subalpine Forest-alpine grassland ecotones in the Spanish Central Pyrenees. Forest Ecology and Management, v. 134, p. 1-16, 2000.

CAPRETZ, R. L. Análise dos padrões espaciais de árvores em quatro formações florestais do Estado de São Paulo, através de análises de segunda ordem, como a função K de Ripley. 2004. 79 p. Dissertação (Mestrado em Ecologia de Agroecossistemas) - Escola Superior de Agricultura Luiz de Queiroz, Universidade de São Paulo, Piracicaba.

CARVALHO, P. E. R. Espécies florestais brasileiras. Brasília: Embrapa Informação Tecnológica; Colombo: Embrapa Florestas, 2003. 1039 p.

CONDIT, R.; ASHTON, P. S.; BAKER, P.; BUNYAVEJCHEWIN, S.; GUNATILLEKE, S. GUNATILLEKE, N.; HUBBELL, S. P.; FOSTER, R. B.; ITOH, A.; LAFRANKIE, J. V.; LEE, H. S.; LOSOS, E.; MANOKARAN, N.; SUKUMAR, R.; YAMAKURA, T.; Spatial Patterns in the Distribution of Tropical Tree Species. Science, v. 288, p. 1414-1418, 2000.

CONNELL, J. H. Diversity in tropical rain forests and coral reefs. Science, v. 199, p. 1302-1310, 1978.

CRESSIE, N. A. C. Statistic for spatial data. New York: John Wiley \& Sons, 1993. 900 p.

CUNHA, U. S. Análise da estrutura espacial horizontal de uma floresta de terra firme da Amazônia. 2003. 126 p. Tese (Doutorado em Ciências Florestais) - Setor de Ciências Agrárias, Universidade Federal do Paraná, Curitiba.

DISPERATI, A. A. Mapeamento florestal da Floresta Nacional de Irati - PR. Curitiba: FUPEF, 18 p. +1 mapa, 1986.

FOX, J. E. D. Constraints on the natural regenaration of tropical moist forest. Forest Ecology and Management, v. 1, p. 37-65, 1976.

HAASE, P. SPPA (Spatial Point Pattern Analysis), versão 2.0.3. 2004. Disponível em: <http://home.tonline.de/home/haasep/sppaload.htm>. Acesso em: 15/12/2007.

KUULUVAINEN, T.; ROUVINEN, S. Post-fire understorey regeneration in boreal Pinnus sylvestris forest sites with different fire histories. Journal of Vegetation Science, v. 11, p. 801-8012, 2000

ODUM, E. P. Ecologia. CBS College Publishing, 1988. Trad.: Rio de Janeiro: Guanabara Koogan, 1983. 434 p.

PÉLISSIER, D. L.; GOREAUD, F. A practical approach to the study of spatial structure in simple cases of heterogeneous vegetation. Journal of Vegetation Science, n. 12, p. 99-108, 2001.

PENTTINEN, A.; STOYAN D.; HENTTONEN, H. M. Marked point processes in forest statistics. Forest Science, v. 38, n. 4 p. 806-824, 1992.

PEREIRA, A. A.; NETTO, S. P.; CARVALHO, L. M. T. Análise da distribuição espacial de jequitibarosa em uma Floresta Estacional Submontana. Rev. Acad. v. 4, n. 2, p. 21-34, 2006.

RIPLEY, B. D. Modelling spatial patterns. Journal of the Royal Statistic Society. v. 39, p. 172-212, 1977.

RODE, R. Avaliação florística e estrutural de uma Floresta Ombrófila Mista e de uma vegetação arbórea estabelecida sob um povoamento de Araucaria angustifolia de 60 anos. 2008. 159 p. Dissertação (Mestrado em Ciências Florestais) - Setor de Ciências Agrárias, Universidade Federal do Paraná, Curitiba.

SCHULZE, E. D.; MOONEY, H. A. Biodiversity and ecosystem function. New York: Springer-Verlang, 1994. 